\title{
Pituitary Surgery and Anesthetic Management: An Update
}

\author{
Surender K Malhotra, Kiran Sharma, Vikas Saini
}

\begin{abstract}
Out of all the brain tumors, $10 \%$ are pituitary tumors. Surgical interventions in this field have advanced and so have techniques of anesthesia and intensive care. Presenting features of the patients with pituitary tumors are often due to excessive or decreased secretion of hormones. Most commonly performed procedure is transsphenoidal pituitary surgery which requires skillful anesthetic technique as a number of associated comorbidities may exist. For a positive surgical result, a team consisting of endocrine surgeon, endocrinologist, neurosurgeon and anesthesiologist is a must. An emphasis is required on preoperative evaluation of airway, endocrinal and neurological status. The understanding of pathophysiology, perioperative anesthetic management, awareness of likely complications and postoperative care, results in successful outcome.
\end{abstract}

Keywords: Pituitary tumors, Anesthesia, Neurosurgery.

How to cite this article: Malhotra SK, Sharma K, Saini V. Pituitary Surgery and Anesthetic Management: An Update. World J Endoc Surg 2013;5(1):1-5.

Source of support: Nil

Conflict of interest: None

\section{INTRODUCTION}

Anesthetic considerations, for a patient undergoing pituitary surgery, are always a challenge to the anesthesiologist. The management requires the knowledge of neurosurgical aspects of anesthesia in general and pituitary disease in particular. The pathophysiology involving the hormonal alterations due to pituitary disease may have significant effect on the outcome of the surgery. The perioperative anesthetic considerations also depend on the technique of surgery. ${ }^{1}$

Pituitary gland weighs 0.5 to $0.9 \mathrm{gm}$ and $15 \times 10 \mathrm{~mm}$ in size. $^{2}$ The gland lies in sella turcica at the base of skull. Superior relations of the gland are hypothalamus and third ventricle. Anterior and posterior relations are sphenoid sinuses and sphenoid clivus respectively. Laterally, it is related to cavernous sinus, internal carotid arteries and cranial nerves III to VI. Pituitary gland has two lobes, anterior and posterior. The anterior lobe (adenohypophysis) forms two-third of the gland. Pituitary gland lies outside the blood-brain barrier. Blood supply to the gland is from branches of internal carotid; inferior and superior hypophyseal arteries. Venous drainage from pituitary gland goes to cavernous sinuses and internal jugular vein.

Hormones secreted by anterior pituitary are growth hormone (GH), adrenocorticotropic hormone (ACTH), thyroid-stimulating hormone (FSH), luteinizing hormone $(\mathrm{LH})$, prolactin, thyroid stimulating hormone (TSH) and endorphins. Posterior pituitary (neurohypophysis) secretes antidiuretic hormone (ADH) and oxytocin.

Clinical presentations of pituitary gland may be of three types: Firstly, due to increased secretions of hormones; secondly, due to decreased secretions of hormones and, thirdly, due to mass effects.

\section{PREOPERATIVE CONSIDERATIONS}

To assess the degree of pituitary functions, an adequate preoperative assessment and endocrinology consultation should be taken. Hormonal and antihypertensive medications should be administered till the day of surgery. To exclude lesions, like hydrocephalus, computed tomography $(\mathrm{CT})$ or preferably magnetic resonance imaging (MRI) should be performed. Documentation of visual fields is mandatory. Nasal obstruction after the procedure due to packs must be explained to the patient. ${ }^{3}$

\section{CARDIOVASCULAR EVALUATION}

Problems, such as coronary artery disease, arrhythmias, left ventricular hypertrophy, valvular heart diseases, congestive heart failure and cardiomyopathies are quite common in pituitary disorders. ${ }^{4-6}$ In cases of obstructive sleep apnea, pulmonary hypertension may occur resulting in respiratory problems after the surgery. Hypertension occurs in Cushing's disease and acromegaly. ${ }^{4,5}$ Cardiac diseases cause mortality in acromegaly patients especially due to hypertension and left ventricular hypertrophy. ${ }^{7,8} \mathrm{ST}$ and $\mathrm{T}$ wave changes and conduction block are frequently observed during stress. ${ }^{9,10}$

\section{AIRWAY DIFFICULTY}

Hypertrophy of the soft tissues of the nose, tongue, turbinates and epiglottis is observed following increased release of GH. Change in voice may caution the stenosis of larynx. ${ }^{1}$ Facial features may be course and bony prominence may lead to prognathism. ${ }^{11}$ Thyroid goiter may be present in acromegaly patients causing compression of trachea. ${ }^{1,12}$ A thorough assessment of airway is mandatory in acromegaly patients. ${ }^{13}$ A preoperative flow volume studies and indirect laryngoscopy is recommended. ${ }^{14,15}$ A history of snoring and daytime sleep may guide the anesthesiologist to manage perioperative airway. ${ }^{12,13}$ 


\section{PROLACTINOMAS}

These are most common kind of secretory pituitary tumors. Frequently, these are microadenomas usually seen in female population. Big size macroadenomas $(>1 \mathrm{~cm})$ affect males and may lead to visual problems due to compression of optic nerve. MRI and estimation of prolactin (>400 mU/l) are diagnostic. Bromocriptine administration is the drug of choice in treating these tumors but it may cause perioperative hypotension and nausea. If there is no response to medical therapy and cerebrospinal fluid (CSF) leak occurs, surgery is indicated. ${ }^{16}$

\section{ACROMEGALY (EXCESS OF GH)}

Acromegaly is a chronic disease involving various systems and is due to excessive release of GH from macroadenoma. It occurs mostly during fourth or fifth decade of life. Anesthesiologist may find difficulty in mask ventilation, laryngoscopy and intubation due to large tongue and receding chin. However, cricoid pressure and tube exchanger may be useful in difficult intubation. ${ }^{17}$ Awake intubation, using fiberoptic bronchoscope, is the method of choice. Majority of these patients have history of obstructive sleep apnea (OSA) and may pose respiratory and cardiovascular problems in postoperative period. ${ }^{18}$ Muscle disorders and scoliosis may further worsen the situation. In addition, these patients may have cardiac problems, such as hypertension, left ventricular hypertrophy, arrhythmias, coronary artery disease and cardiomyopathy. Echocardiography may indicate the pulmonary pressures and left ventricular functions. Peripheral venous access and arterial cannulation may be challenging. Increase in blood sugar level is a common finding. Respiratory care and monitoring after the surgery are undertaken in critical care unit.

\section{CUSHING'S DISEASE (EXCESS OF ACTH)}

Problems of Cushing's disease are features of cardiovascular disease, diabetes mellitus and immunosuppression. Delicate skin and osteoporosis may cause difficulty in venous access and incidence of spontaneous fractures respectively. ${ }^{19,20}$ Majority of patients have hypertension, coronary artery disease and left ventricular hypertrophy leading to morbidity during and after surgery. ${ }^{1}$ Intraoperative bleeding is a frequent problem. Obesity may complicate the airway management. ${ }^{20}$ These patients are prone to aspiration as gastric reflux is frequent. ${ }^{12}$ Postoperative ventilation may be required owing to pre-existing myopathy. ${ }^{20}$

\section{HYPOPITUITARISM}

In case, pituitary tropic hormones are normal and peripheral hormones are decreased, hypopituitarism is the likely diagnosis. ${ }^{19}$ Features of this situation are loss of consciousness, vision loss or headache and may require emergency surgical intervention. These patients are prone to water intoxication and low blood sugar levels and may prove sensitive to anesthetic drugs leading to prolonged recovery. ${ }^{21}$ The patients who have reduced ACTH level must be given glucocorticoid cover to avoid hypoadrenal crisis. ${ }^{1}$ It is mandatory to replace thyroxin $(50-150 \mu \mathrm{g} /$ day $)$. Intraoperative hypotension should be countered with vasopressors.

In addition, there may be 'mass effect', i.e. if macroadenomas is $>1 \mathrm{~cm}$ it may compress optic nerve leading to vision impairment. Large lesions may even increase the intracranial pressure (ICP) resulting in hydrocephalus.

\section{PITUITARY SURGERY: TECHNIQUES}

Pituitary surgery is indicated, when medical therapy fails or as primary therapy for some pituitary lesions. Currently, most of the procedures are carried out by transsphenoidal technique. Transcranial approach is used for large tumors or when transsphenoidal technique is not successful. There is minimal bleeding as well as direct access is possible by trans-sphenoidal technique. However, risks of this approach are CSF rhinorrhea, vascular trauma, meningitis, cranial nerve damage and vasospasm, leading to cerebral ischemia. $^{22}$

Local application of local anesthetics and vasoconstrictor helps reducing the bleeding in surgical field. Topical phenylephrine may be preferred as adrenaline may lead to hypertension in Cushing's disease. Cocaine is not popular as it causes arrhythmias and coronary spasm. Safe vasoconstrictor is xylometazoline for topical use. ${ }^{23}$ Lignocaine (1\%) with adrenaline 1:200,000 is recommended for effective analgesia and vasoconstriction. ${ }^{24}$ In case of hypertension, beta-blockers and nitroglycerine may be required. ${ }^{25}$

\section{STEROID SUPPLEMENTATION}

Glucocorticoids cover in patients with hypopituitarism is commenced an evening before the surgery (100 $\mathrm{mg}$ of hydrocortisone intravenously), repeated before start of surgery as well as in the evening. ${ }^{26}$ Perioperative glucocorticoid cover in all patients with Cushing's disease is mandatory. To confirm ACTH deficiency, cortisol test is recommended before administration of steroid cover is decided. In case of abnormal results, usual maintenance doses of glucocorticoid should be started (Table 1). If no ACTH deficiency is detected, no glucocorticoid supplementation is required.

\section{LUMBAR CSF DRAIN}

Indication of lumbar CSF drain is massive suprasellar extension of tumor. The level of insertion of this drain should 
Table 1: Supplementation of glucocorticoids

\begin{tabular}{lll}
\hline Plasma cortisol levels $(\mathrm{nmol} / \mathrm{l})$ & Hydrocortisone dose $(\mathrm{mg})$ & Tests required \\
\hline$<100$ & $15-30 \mathrm{mg} / \mathrm{d}$ & Nil \\
$100-250$ & $10-20 \mathrm{mg} / \mathrm{d}$ & HPA tests required \\
$250-450$ & Only during stress & HPA tests recommended \\
$>450$ & No supplementation & No further tests needed \\
\hline
\end{tabular}

HPA: Hypothalamic pituitary axis

be L3-4 interspace. The catheter is introduced in a cephalad direction. ${ }^{13}$ Five to $10 \mathrm{ml}$ of air or normal saline is introduced into the subarachnoid space, which by pressure effect pushes the suprasellar extension of the tumor into the surgical field, leading to complete excision of the tumor. ${ }^{1}$ This procedure must be performed under absolute sterile setting. A Valsalva or Queckenstedt's maneuver is a satisfactory alternative in case there is no lumbar drain. ${ }^{27}$

\section{CONTROLLED HYPERCAPNIA}

A permissive hypercapnia with $\mathrm{PaCO}_{2}$ of $60 \mathrm{~mm} \mathrm{Hg}$ is recommended as successful way to increase the ICP to shift the suprasellar part of a tumor into the sella for easy surgical excision. ${ }^{28}$ A high normocapnia $(40-45 \mathrm{~mm} \mathrm{Hg}$ ) is also recommended for the purpose..$^{22}$ However, hypercarbia may result in hypertension, tachycardia and a reduced myocardial perfusion.

\section{GOALS OF ANESTHESIA}

The aim of anesthetic technique must be targeted toward hemodynamic stability, maintaining adequate cerebral oxygenation and a normal ICP. ${ }^{29}$ There should be an ideal surgical exposure and smooth recovery at the end of surgery. Aim should be the prevention and management of intraoperative complications. Intra-arterial measurement of blood pressure is mandatory in all the patients. Depending on the coexisting conditions of the patient, central venous pressure monitoring may be considered.

\section{AIRWAY MANAGEMENT}

In patients, such as acromegaly and Cushing's, mask ventilation may not be easy.

Fiberoptic intubation, that may be awake and oral, is the recommended technique in case there is recognized difficult airway. In acromegaly, the difficult tracheal intubation may not be predicted.

Southwick and $\mathrm{Katz}^{30}$ defined four grades of airway involvement in acromegalic patients. Obesity in patients with Cushing's syndrome may contribute in making the airway difficult, particularly the mask ventilation.

\section{ANESTHETIC TECHNIQUE}

All the patients should have large-bore intravenous access for rapid volume resuscitation.
A reinforced orotracheal tube is recommended, positioned in the left corner of the mouth.

A throat pack is inserted and ensured that it is removed before extubation.

While deciding the technique of anesthesia, the basic principles of neuroanesthesia should be followed.

Choice of anesthetics is made on the presence of coexisting diseases and past history of anesthesia exposure. One of the two techniques, i.e. total intravenous anesthesia (TIVA) or balanced anesthesia using muscle relaxants with inhalational agents may be selected. ${ }^{31}$ Only short-acting agents should be used to facilitate rapid recovery, because postoperative airway maintenance is a problem. It is prudent to avoid nitrous oxide in case there is increased ICP. ${ }^{26}$ Majority of the inhalational agents, such as isoflurane, sevoflurane and desflurane increase the cerebral blood flow. This results in rise in ICP but it depends on duration of their use. Producing hypocarbia by hyperventilation reduces the chances of rise in ICP. Isoflurane causes minimum increase in ICP out of all volatile agents. ${ }^{32}$

In case of raised ICP, TIVA is the better choice. ${ }^{26}$ For rapid recovery, induction agents like propofol and analgesics, such as remifentanil are preferred. To ensure quick emergence, inhalational agents like sevoflurane or desflurane should be used since their blood solubility is low. Neuromuscular blocking agents are must for complete relaxation and effective ventilation.

If the surgery is done in sitting position, chances of air embolism increase in case some cavernous sinus ruptures. During transsphenoidal surgery, a negligible blood loss occurs unless injury to a big vessel, such as carotid artery occurs. Valsalva maneuver may be used to test for any CSF leak after excision of tumor. Before its reconstruction, sella is packed with autologous fat to prevent any CSF leak. The administration of perioperative paracetamol is also recommended due to its highly favorable risk: benefit ratio. ${ }^{33}$ NSAIDs have been linked to postoperative hematoma formation ${ }^{34}$ but it is controversial. Tramadol is less effective and causes more sedation and postoperative nausea and vomiting. ${ }^{35}$

\section{MONITORING}

Routine monitoring, such as ECG, pulse oximetry, $\mathrm{EtCO}_{2}$ and invasive arterial blood pressure are carried out. Majority 
of the patients with Cushing's disease and acromegaly may have features of cardiovascular disease that increase the anesthesia-related morbidity, particularly if intraoperative hemodynamic instability occurs. These patients require invasive arterial blood pressure monitoring in case of fluctuations in BP occurs. ${ }^{36}$ Visual evoked potential monitoring is employed, if tumor is affecting the visual field. Since, this monitor has sensitivity to anesthetics, results are not reliable. ${ }^{26}$

\section{POSITIONING DURING SURGERY}

For transsphenoidal surgery, a head up position (operative field above the level of the heart) is required as it minimizes bleeding during the surgical procedure, though the chances of venous embolism increase in this position. ${ }^{37}$ The neck of the patient is tilted laterally to the left, extended and secured in a Mayfield clamp. This immobilizes the head and facilitates application of the stereotactic frame, allowing the surgeon a midline approach. The elderly patients have more rigid necks, so the table can be tilted laterally to obtain the face-on position for easy access to the field.

\section{INTRAOPERATIVE COMPLICATIONS}

Despite the semi-sitting position, air embolism is infrequent. Bleeding from carotid artery damage is not common but is a serious complication if it takes place. Other structures likely to be damaged are cranial nerves II to VI, optic nerves/ chiasm and venous sinuses. Transcranial approach may result in all the complications like any other craniotomies. Anticonvulsant prophylaxis is a must. Lesion of olfactory nerve may lead to anosmia.

\section{EMERGENCE}

Pharyngeal packs are removed at the end of the procedure and suctioning of mouth cavity is carried out. Once the patient starts breathing spontaneously and the reflexes return, extubation is undertaken. If patient is awake after reversal, it is easy to assess him neurologically. Ensure that patient has satisfactory respiration and hemodynamically stable. Coughing or bucking is avoided as it may precipitate hemorrhage, dislodge the nasal pack and may cause CSF leakage.

\section{POSTOPERATIVE CARE}

After surgery, all the patients should be kept in a high dependency area due to a risk of airway compromise. Patients with history of OSA are at bigger threat. Nasal CPAP is contraindicated after transsphenoidal surgery as it may lead to tension pneumocephalus. There should be a close watch at the level of consciousness, eye movements and visual fields. These should be tested regularly and any worsening discussed with the surgeon for any further action. ${ }^{38}$ Neuroendocrine abnormalities after pituitary surgery are common. Diabetes insipidus (DI) occurs within the first 24 hours and disappears in a week. Desmopressin (nasally or parenteral) is given, if DI persists but beware of hyponatremia. Hormonal replacement therapy is required in all patients after surgery. Steroid replacement therapy is undertaken in a reducing regime. Endocrinologists should be consulted for all replacement therapy, i.e. steroids or hormones. ${ }^{39}$

\section{PITUITARY APOPLEXY}

The term is defined as acute hemorrhagic infarction of a gland whose blood supply is earlier compromised by a tumor or pregnancy. ${ }^{40}$ It may be due to obstetric hemorrhage, sickle cell crisis and head injury. Usually, there is acute failure of anterior lobe function. The posterior lobe function generally remains normal. Common features are severe headache, nausea and vomiting, visual field defects and cranial nerve palsies. It is managed by treating adrenocortical failure with intravenous fluids, urgent transsphenoidal decompression and replacement of hydrocortisone.

\section{CONCLUSION}

Pituitary surgery involves a multidisciplinary approach consisting of endocrinologist, the neurosurgeon, radiologist and the anesthesiologist. Their teamwork and coordination is of immense importance. Preoperative optimization of systemic diseases due to pituitary involvement must be carried out. Appropriate anesthetic management based on patient's disease and surgical procedure should be carried out intraoperatively. Fast recovery from anesthesia is vital because early neurologic assessment can disclose most serious surgical complications. Follow-up of all the patients with endocrinologist to assess their hormonal status is mandatory.

\section{REFERENCES}

1. Razis PA. Anesthesia for surgery of pituitary tumors. Int Anesthesiol Clin 1997;35:23-34.

2. Nussey SS, Whitehead SA. The pituitary gland. In: Nussey SS, Whitehead SA (Eds). Endocrinology: An integrated approach. London: Bios Scientific Publishers Ltd 2001;283-331.

3. Nemergut EC, Dumont AS, Barry UT, et al. Perioperative management of patients undergoing transsphenoidal pituitary surgery. Anesth Analg 2005;101:1170-81.

4. Herrmann BL, Bruch C, Saller B, et al. Acromegaly: Evidence for a direct relation between disease activity and cardiac dysfunction in patients without ventricular hypertrophy. Clin Endocrinol (Oxf) 2002;56:595-602.

5. Muiesan ML, Lupia M, Salvetti M, et al. Left ventricular structural and functional characteristics in Cushing's syndrome. J Am Coll Cardiol 2003;41:2275-79. 
6. Colao A, Cuocolo A, Marzullo P, et al. Is the acromegalic cardiomyopathy reversible? Effect of 5-year normalization of growth hormone and insulin-like growth factor I levels on cardiac performance. J Clin Endocrinol Metab 2001;86:1551-57.

7. Lopez-Velasco R, Escobar-Morreale HF, Vega B, et al. Cardiac involvement in acromegaly: Specific myocardiopathy or consequence of systemic hypertension? J Clin Endocrinol Metab 1997;82:1047-53.

8. Ciulla M, Arosio M, Barelli MV, et al. Blood pressure independent cardiac hypertrophy in acromegalic patients. J Hypertens 1999;17:1965-69.

9. Kahaly G, Olshausen KV, Mohr-Kahaly S, et al. Arrhythmia profile in acromegaly. Eur Heart J 1992;13:51-56.

10. Rodrigues EA, Caruana MP, Lahiri A, et al. Subclinical cardiac dysfunction in acromegaly: Evidence for a specific disease of heart muscle. Br Heart J 1989;62:185-94.

11. Seidman PA, Kofke WA, Policare R, et al. Anaesthetic complications of acromegaly. Br J Anaesth 2000;84:179-82.

12. Smith M, Hirsch NP. Pituitary disease and anaesthesia. Br J Anaesth 2000;85:3-14.

13. Hirsch N, Jewkes D. Anaesthesia for pituitary surgery. In: Powell M, Lightman SL (Eds). The management of pituitary tumours: A handbook. Edinburgh: Churchill Livingstone 1996;141-44.

14. Chan VWS, Tindal S. Anaesthesia for transsphenoidal surgery in a patient with extreme gigantism. Br J Anaesth 1988;60: 464-68.

15. Summors AC, Erskine RE. Anaesthesia for neurosurgery without craniotomy. In: Matta B, Menon D, Turner J (Eds). Textbook of neuroanaesthesia and critical care. London: Greenwich Medical Media 2000;53-253.

16. Nomikos P, Buchefelder M, Falbusch R. Current management of prolactinomas. J Neurooncol 2001;54:139-50.

17. Nemergut EC, Zuo Z. Airway management in patients with pituitary disease. J Neurosurg Anesthesiol 2006;18:73-77.

18. Melmed S. Acromegaly pathogenesis and treatment. J Clin Invest 2009;119:3189-202.

19. Hurley DM, Ho KKY. Pituitary disease in adults. MJA 2004;180:419-25.

20. Levy A, Lightman SL. Fortnightly review: Diagnosis and management of pituitary tumours. BMJ 1994;308:1087-91.

21. Matjasko MJ. Anesthetic considerations in patients with neuroendocrine disease. In: Cottrell J, Smith D (Eds). Anesthesia and neurosurgery (4th ed). St Louis: Mosby 2001;591-607.

22. Lim M, Williams D, Maartens N. Anaesthesia for pituitary surgery. J Clin Neurosci 2006;13:413-18.

23. Campbell JP, Campbell CD, Warren DW, et al. Comparison of the vasoconstrictive and anesthetic effects of intranasally applied cocaine vs xylometazoline/lidocaine solution. Otolaryngol Head Neck Surg 1992;107:697-700.

24. Keegan MT, Atkinson JLD, Kasparbauer JL, et al. Exaggerated hemodynamic responses to nasal injection and awakening from anesthesia in a Cushingoid patient having transsphenoidal hypophysectomy. J Neurosurg Anesthesiol 2000;12:225-29.

25. Chelliah YR, Manninen PH. Hazards of epinephrine in transsphenoidal pituitary surgery. J Neurosurg Anesthesiol 2000;14:43-46.

26. Powell M, Lightman SL. Postoperative management. In: Powell M, Lightman (Eds). The management of pituitary tumours: A handbook. London: Churchill Livingstone 1996;145-58.
27. Jane JA Jr, Thapar K, Kaptain GJ, et al. Pituitary surgery: Transsphenoidal approach. Neurosurgery 2002;51:435-42.

28. Korula GT, George SP, Rajshekhar V, et al. Effect of controlled hypercapnia on cerebrospinal fluid pressure and operating conditions during transsphenoidal operations for pituitary macroadenoma. J Neurosurg Anesthesiol 2001;13:255-59.

29. Ana H, Juranko K, Aleksandar G, et al. Anesthetic management of patients undergoing pituitary surgery. Acta Clin Croat 2011; 50:209-16.

30. Southwick JP, Katz J. Unusual airway difficulty in the acromegalic patient: Indications for tracheostomy. Anesthesiology 1979;51:72-73

31. Cafiero T, Cavallo LM, Frangiosa A, et al. Clinical comparison of remifentanil-sevoflurane vs remifentanil-propofol for endoscopic endonasal transsphenoidal surgery. Eur J Anaesthesiol 2007;24:441-46.

32. Morgan GE Jr, Mikhail MS, Murray MJ, et al. Clinical anesthesiology. Stamford: McGraw-Hill Companies, Inc 2002; 631-46.

33. Hyllested M, Jones S, Pederson JL, et al. Comparative effect of paracetamol, NSAIDs or their combination in postoperative pain management: A qualitative review. Br J Anaesth 2002;88: 199-214.

34. Palmer J, Sparrow O, Iannotti F. Postoperative haematoma: A 5 -year survey and identification of avoidable risk factors. Neurosurgery 1994;35:1061-64.

35. Jeffrey $H$, Charlton $P$, Mellor D, et al. Analgesia after intracranial surgery: A double-blind, prospective comparison of codeine and tramadol. Br J Anaesth 1999;83:245-49.

36. Laws ER Jr, Sheehan JP. Pituitary surgery - a modern approach. Basel: Karger 2006;185-205.

37. Gadhinglajkar SV, Sreedhar R, Bhattacharya RN. Carotid artery injury during transsphenoidal resection of pituitary tumor: Anesthesia perspective. J Neurosurg Anesthesiol 2003;15: 323-26.

38. Vance ML. Perioperative management of patients undergoing pituitary surgery. Endocrinol Metab N Am 2003;32:355-65.

39. Menon R, Murphy PG, Lindley AM. Anaesthesia and pituitary disease. Cont Educ Anaesth Crit Care Pain 2011;11(4):133-37.

40. Nawar RN, AbdelMannan D, Selman WR, et al. Pituitary tumor apoplexy: A review. J Intensive Care Med 2008;23(2):75-90.

\section{ABOUT THE AUTHORS}

\section{Surender K Malhotra (Corresponding Author)}

Professor, Department of Anesthesia and Intensive Care, Postgraduate Institute of Medical Education and Research, Chandigarh, India e-mail: drskmalhotra4@gmail.com

\section{Kiran Sharma}

Senior Resident, Department of Anesthesia and Intensive Care, Postgraduate Institute of Medical Education and Research Chandigarh, India

\section{Vikas Saini}

Assistant Professor, Department of Anesthesia and Intensive Care, Postgraduate Institute of Medical Education and Research Chandigarh, India 